\title{
Use of venoarterial extracorporeal membrane oxygenation in fulminant chagasic myocarditis as a bridge to heart transplant
}

Andre Rodrigues Duraes ${ }^{1 *}$, Fernando Augusto Marinho dos Santos Figueira ${ }^{2}$, Andre Rabelo Lafayette ${ }^{3}$ and Juliana de Castro Solano Martins ${ }^{4}$

${ }^{1}$ Specialist in cardiology by the Brazilian Society of Cardiology, Professor of Cardiology at Universidade do Estado da Bahia, Brazil

${ }^{2}$ Specialist in cardiovascular surgery by the Brazilian Society of Cardiovascular Surgery, Brazil

${ }^{3}$ Specialist in cardiology by the Brazilian Society of Cardiology, Brazil

${ }^{4}$ Medical Student at Universidade Federal da Bahia (UFBA), Brazil

A 17-year-old Brazilian male presented with progressive dyspnea for 15 days and worsening in the last 24 hours, being admitted on $04 / 04 / 15$ in respiratory failure and cardiogenic shock with multiple organ dysfunction. Echocardiography showed left ventricule ejection fraction (LVEF) of $11 \%$, severe diffuse hypokinesia and systolic pulmonary artery pressure (sPAP) of $50 \mathrm{mmHg}$, developing need for hemodynamic support with dobutamine $(20 \mathrm{mcg} / \mathrm{kg} / \mathrm{min})$ and noradrenaline $(1,7 \mathrm{mcg} / \mathrm{kg} / \mathrm{min})$. After 48 hours with no clinical or hemodynamic improvement, extracorporeal membrane oxygenation (ECMO) was implanted. Hemodynamic (noradrenaline dropped to $0,21 \mathrm{mcg} / \mathrm{kg} / \mathrm{min}$ ), systemic perfusion (lactate of $17 \mathrm{mmol} / \mathrm{L}$ dropped to $2,5 \mathrm{mmol} / \mathrm{L}$ and increase diuresis volume), renal (serum creatinine from 6.5 to $1.2 \mathrm{mg} / \mathrm{dL}$ ) and liver function (international normalized ratio 8.5 to 1.2 ) improvement was presented, but without cardiac

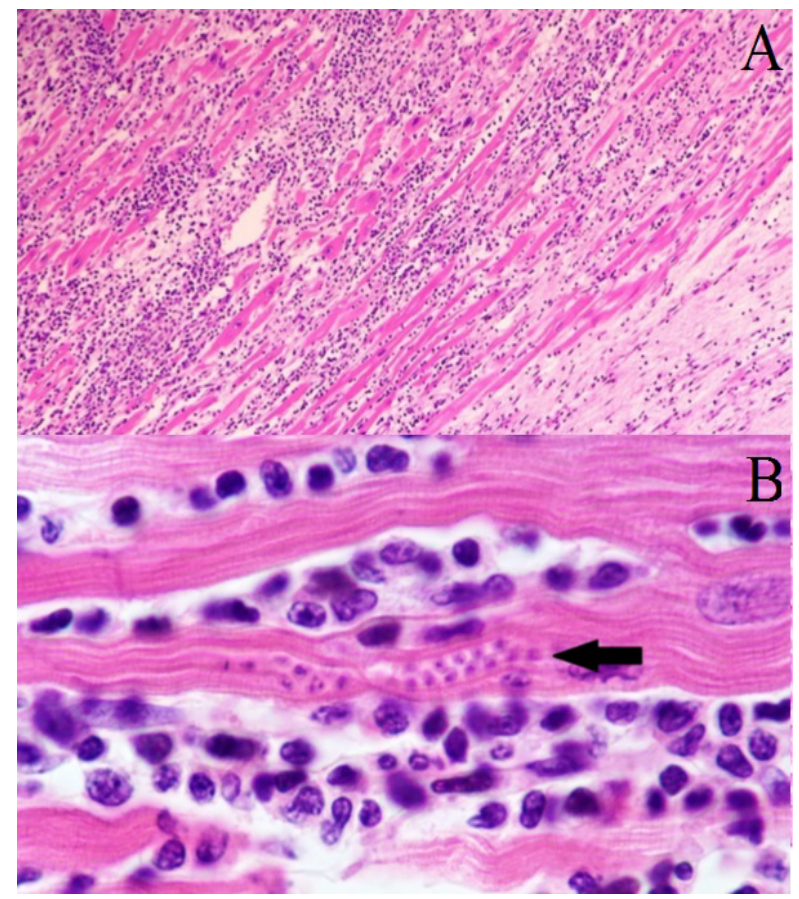

Figure 1. Patient and ECMO equipment positioningduring air transport from Salvador to Recife (Brazil).

Histology of explanted heart sample. Panel A, photomicrograph $(\times 400)$ of an haematoxylin and eosin stained sample. In Panel B, at this magnification $(\times 1000)$ the organisms (amastigotes of Trypanosoma cruzi) within a myocyte (arrow) and the adjacent inflammatory response are more clearly seen. function recovery after 72 hours opting for transfer to another hospital.

Air transport was conducted from Salvador to Recife on 09/04/15 (travelled distance of 466 miles). Heart transplant was conducted on $11 / 04 / 15$, with excellent performance, rapid recovery of liver and kidney function and good graft function. Histopathology of the explanted heart showed chronic active myocarditis and amastigotes of Trypanosoma cruzi (Figure 1), showing chagasic cardiomyopathy.

Myocarditis is an inflammatory disease due to infectious or noninfectious conditions. Clinical manifestation is variable, ranging from subclinical presentation to refractory heart failure and cardiogenic shock [1]. Mechanical circulatory support with intra-aortic balloon or ventricular assist devices should be considered in cases refractory to medical therapy [2]. Several reports suggest that the use of ECMO in patients presenting severe and refractory myocarditis is an option as a bridging therapy to heart transplant when there is no spontaneous recovery of ventricular function $[3,4]$. The venoarterial ECMO can be implanted percutaneously at the bedside and can be kept for several weeks with proper care. It is the preferred device when biventricular dysfunction is presented and often promotes rapid improvement of hemodynamic status, oxygenation parameters and organ function [5]. In face of heart function improvement, the mechanical support device can be progressively withdrawn, but when cardiac function impairment is maintained, the treatment of choice would be a long-term device or heart transplant $[3,4]$. In the presented case, ECMO was used on a patient with multiple organ failure secondary to a defined and refractory cardiogenic shock. The benefit of the method was unquestionable even in advance stages of renal and liver failure. The patient presented partial recovery of the affected systems, making possible the implementation of the definitive therapy to severe myocarditis: heart transplant. In a 6-month follow-up outpatient consult, the patient presented himself in good health.

\section{Acknowledgments}

We would like to thank the heart transplant team at the Hospital

Correspondence to: Andre Rodrigues Duraes, $\mathrm{PhD}$, Specialist in cardiology by the Brazilian Society of Cardiology, Professor of Cardiology at Universidade do Estado da Bahia, Rua Alberto Silva, No 439, Itaigara, 41815-000 - Salvador Bahia, Brazil, Tel: 5571 9188-8399; E-mail: andreduraes@gmail.com

Received: October 01, 2015; Accepted: October 23, 2015; Published: October 27,2015 
Ana Nery and the Instituto de Medicina Integral Professor Fernando Figueira.

\section{Disclosure statement}

The authors have no conflicts of interest to disclose.

\section{References}

1. Montera MW, Mesquita ET, Colafranceschi AS, Oliveira Jr AC Jr, Rabischoffsky A, et al. (2013) I Brazilian guidelines on myocarditis and pericarditis. Arq Bras Cardiol 100: 1-36. [Crossref]
2. Kindermann I, Barth C, Mahfoud F, Ukena C, Lenski M, et al. (2012) Update on myocarditis. J Am Coll Cardiol 59: 779-792. [Crossref]

3. Atluri P, Ullery BW, MacArthur JW, Goldstone AB, Fairman AS, et al. (2013) Rapid onset of fulminant myocarditis portends a favourable prognosis and the ability to bridge mechanical circulatory support to recovery. Eur J Cardiothorac Surg 43: 37982. [Crossref]

4. Chen JM, Spanier TB, Gonzalez JJ, Marelli D, Flannery MA, et al. (1999) Improved survival in patients with acute myocarditis using external pulsatile mechanical ventricular assistance. J Heart Lung Transplant 18: 351-357. [Crossref]

5. Sayer GT, Baker JN, Parks KA (2012) Heart rescue: the role of mechanical circulatory support in the management of severe refractory cardiogenic shock. Curr Opin Crit Care 18: 409-416. [Crossref]

Copyright: (C)2015 Duraes AR. This is an open-access article distributed under the terms of the Creative Commons Attribution License, which permits unrestricted use, distribution, and reproduction in any medium, provided the original author and source are credited. 